\title{
Increased PKM activity impedes lateral movement of GluA2-containing AMPA receptors
}

\author{
Nam-Kyung Yu ${ }^{1 \dagger}$, Heesoo Uhm³, 2,4,5†, Jaehoon Shim ${ }^{1 \dagger}$, Jun-Hyeok Choi ${ }^{1}$, Sangsu Bae ${ }^{6}$, Todd Charlton Sacktor ${ }^{7,8,9}$, \\ Sungchul Hohng ${ }^{2,3,4,5^{*}}$ and Bong-Kiun Kaang ${ }^{1,10^{*}}$
}

\begin{abstract}
Protein kinase $M$ zeta (PKMC), a constitutively active, atypical protein kinase $C$ isoform, maintains a high level of expression in the brain after the induction of learning and long-term potentiation (LTP). Further, its overexpression enhances long-term memory and LTP. Thus, multiple lines of evidence suggest a significant role for persistently elevated PKM levels in long-term memory. The molecular mechanisms of how synaptic properties are regulated by the increase in PKM , however, are still largely unknown. The a-amino-3-hydroxy-5-methyl-4-isoxazolepropionic acid (AMPA) receptor (AMPAR) mediates most of the fast glutamatergic synaptic transmission in the brain and is known to be critical for the expression of synaptic plasticity and memory. Importance of AMPAR trafficking has been implicated in PKM $\zeta$-mediated cellular processes, but the detailed mechanisms, particularly in terms of regulation of AMPAR lateral movement, are not well understood. In the current study, using a single-molecule live imaging technique, we report that the overexpression of $\mathrm{PKM} \zeta$ in hippocampal neurons immobilized GluA2-containing AMPARs, highlighting a potential novel mechanism by which PKM may regulate memory and synaptic plasticity.
\end{abstract}

Keywords: PKM , PKM-zeta, AMPAR, Quantum dots, Single molecule imaging, GluA2, LTP, Lateral diffusion

\section{Introduction}

Long-term memory and its cellular analog long-term potentiation (LTP), undergo induction and maintenance processes involving distinct mechanisms [1]. Whereas induction is believed to be regulated by post-translational modification of pre-existing proteins at the synapse, maintenance is thought to require new protein synthesis during brief time windows after learning followed by the persistent activity of newly synthesized proteins such as protein kin-

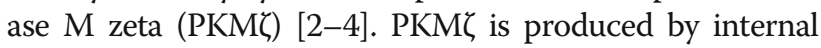
transcription from the $\mathrm{PKC}$ gene, lacking the autoinhibitory domain of $\mathrm{PKC} \zeta$ and is thus autonomously active.

Numerous studies have shown that the administration of a PKM inhibitor, zeta inhibitory peptide (ZIP), during the maintenance phase erased various types of memory

\footnotetext{
* Correspondence: shhong@snu.ac.kr; kaang@snu.ac.kr

tEqual contributors

2Department of Physics and Astronomy, Seoul National University, Seoul,

South Korea

${ }^{1}$ Department of Biological Sciences, College of Natural Sciences, Seoul

National University, Seoul, South Korea

Full list of author information is available at the end of the article
}

and reversed LTP, suggesting PKM $\zeta$ as a key molecule for memory maintenance [5-8]. However, this has been challenged by new findings where the genetic deletion of PKM $\zeta$ in mice did not impair the formation of longterm memory and LTP $[9,10]$. Moreover, ZIP still impaired memory and LTP in PKM $\zeta$-null mice, questioning the specificity of ZIP. Although the exact mechanisms how ZIP has abolished long-term memory and LTP remain to be sorted out, it has been consistently shown that PKM $\zeta$ protein level increases after learning or LTPinducing stimuli $[9,11,12]$. The up-regulation has been reported to last up to 1 month, much longer than for most other proteins known to be induced after learning [12]. In that study, the persistence of the up-regulation was correlated with the persistence of memory. Importantly, PKM $\zeta$-specific antisense oligonucleotide that prevents the up-regulation impaired the late-LTP and memory, suggesting the necessity of the up-regulation [11, 12]. Moreover, a recent study demonstrated that another type of atypical protein kinase $\mathrm{C}$, iota/lambda $(\mathrm{PKCl} / \lambda)$, which can be also blocked by ZIP, compensates the PKM 's roles 
for late-LTP and certain types of long-term memory in $\mathrm{PKM}$-null mice, whereas in wild-type mice the $\mathrm{PKCl} / \lambda$ antagonist had no apparent effect [11]. In addition, a second study using shRNA to knockdown either PKM $\mathrm{PKCl} / \lambda$ found that suppression of $\mathrm{PKM} \zeta$, but not $\mathrm{PKCl} / \lambda$, disrupted previously established long-term memory [13]. Therefore, in normal conditions without compensation due to the prolonged absence of PKM $\zeta$, the persistent increase of PKM $\zeta$ following learning or an LTP stimulus may play a crucial role in the maintenance of memory and LTP. The importance of PKM $\zeta$ in memory has been further supported by the studies showing that PKM $\zeta$ overexpression enhances synaptic transmission and plasticity [14] as well as long-term memory $[15,16]$.

However, the molecular mechanisms underlying how the increased PKM Contributes to synaptic transmission and memory maintenance are not well understood. The $\alpha$-amino-3-hydroxy-5-methyl-4-isoxazolepropionic acid (AMPA) receptor (AMPAR) is the major glutamate receptor in the brain that mediates fast synaptic transmission. Its level at the synaptic surface is critical for determining synaptic strength and thus its regulation is crucially involved in not only synaptic plasticity and memory but also disorders such as chronic pain and itch [17-21]. The level of surface AMPARs can be regulated by vesicle trafficking between membrane and intracellular compartments via exocytosis and endocytosis $[22,23]$. Previous studies have suggested that PKM $\zeta$ regulates the synaptic level of AMPA receptor by promoting the interaction of GluA2-containing AMPARs with NSF and disrupting the internalization of AMPAR via PICK1/AP2 [24, 25]. In addition to membrane trafficking, the lateral movement of AMPAR on the cell membrane and its diffusional trapping at synapses have emerged as central mechanisms determining the distribution of AMPAR [24]. However, whether PKM $\zeta$ can act on the lateral mobility of membrane AMPAR has not been explored.

In the current report, therefore, we used single quantumdot (Qdot) live-imaging to examine the possibility that $\mathrm{PKM} \zeta$ regulates the lateral diffusion of AMPARs.

\section{Methods}

\section{Dissociated rat hippocampal neuron culture and nucleofection}

The culture was prepared by following the protocol from our previous study [26] with modifications for nucleofection and imaging. A Lab-tek II 4 chamber slide glass (Nunc, 154,534) was first coated with poly-D-lysine in sodium borate buffer ( $\mathrm{pH}$ 8.5), followed by laminin. Dissociated hippocampal cells from E18 rat embryos were mixed with DNA constructs (330 ng of each construct) in the strips for nucleofection, following the manufacturer's manual (Lonza). For DNA constructs, pZcb-rtTA3 and
pZtiwb-mCerulean3.0-homer1c were included in every

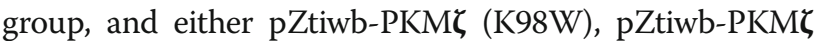
(T227E), or no PKM $\zeta$ (as a control) were added. The nucleofected and non-nucleofected cells were mixed, at a ratio of $2: 1$, and plated at density of 18,000 cells $/ \mathrm{cm}^{2}$ in the plating media. After $3 \mathrm{~h}$ of recovery, media were changed into maintenance media.

\section{Labeling AMPARs}

Neurons at 13-14 DIV were treated with doxycycline $(0.7 \mu \mathrm{g} / \mathrm{mL})$ for 2 days to induce the expression of PKM mutants and mCerulean3.0-homer1c, under the tetO promoter. Following a 10-min incubation with antiGluA2 antibody (MAB397, 1:200) in the imaging buffer (124 mM NaCl, $2.5 \mathrm{mM} \mathrm{KCl}, 1 \mathrm{mM} \mathrm{NaH} \mathrm{PO}_{4}, 2 \mathrm{mM}$ $\mathrm{CaCl}_{2}, 2 \mathrm{mM} \mathrm{MgCl}_{2}, 24.6 \mathrm{mM} \mathrm{NaHCO}, 30 \mathrm{mM}$ Dglucose, $20 \mathrm{mM}$ HEPES, $\mathrm{pH}$ 7.4), the neurons were washed with the imaging buffer twice and incubated with Qdot655 anti-mouse IgG $(\mathrm{H}+\mathrm{L})$ for $2 \mathrm{~min}$ (Invitrogen, Q-11021MP, 1:200). The neurons were then washed with the imaging buffer twice and placed under the microscope for single molecule imaging within 30 min after labeling.

\section{Single molecule localization and tracking}

Neurons were imaged at $37{ }^{\circ} \mathrm{C}$ using an inverted microscope (Olympus IX71, Olympus), equipped with an electron multiplying charge-coupled device camera (Ixon DV897, Andor Technology). The mCerulean3.0Homer1C and Qdot (Qdot655, Thermo Fisher)-AMPAR were excited using blue (473 nm, Blues TM50, Cobolt) and red lasers (640 nm, Cube640-100C, Coherent), respectively. Secondary dendrites (at most 3 different regions per cell) were randomly selected for imaging. A total of 100 consecutive frames were first imaged for mCerulean3.0-Homer1C, while 500 frames were recorded later for Qdot-AMPAR, at $20 \mathrm{~Hz}$ (with an exposure of $50 \mathrm{~ms}$ ). The same protocol was repeated at different positions. The total imaging time for a sample was limited to less than $30 \mathrm{~min}$. The localization and tracking of single Qdots were performed using homemade programs written in MATLAB (Mathworks). To determine the center position, single Qdot images were fitted to a two-dimensional Gaussian surface [27]. When continuous imaging of the Qdot was not possible, due to Qdot blinking, the trajectories of the same Qdot were connected using criteria that the maximal dark period of Qdot was less than 10 frames (i.e., $0.5 \mathrm{~s}$ ) and the maximal positional change was less than 4 pixels (i.e., $280 \mathrm{~nm}$ ) [28]. Synapses were identified using image segmentation of the mCerulean3.0-Homer1C postsynaptic marker, and the corresponding binary mask was then used to sort Qdot-AMPAR trajectories to synaptic or extrasynaptic regions. Diffusion coefficients were calculated using a linear fit of the first 4 points of the 
mean square displacement (MSD) plots versus time. Immobile fractions of the trajectories were determined using the criteria that the logarithm of the diffusion coefficient (in units of $\mu \mathrm{m}^{2} \mathrm{~s}^{-1}$ ) was less than -2.5 .

\section{Immunocytochemistry}

The neurons expressing PKM the same condition used for the Qdot live imaging were fixed using $4 \%$ paraformaldehyde/4\% sucrose in PBS for $15 \mathrm{~min}$ at RT and washed with PBS for 3 times. Cells were permeabilized by PBT $(0.1 \%$ BSA, $0.1 \%$ Triton $\mathrm{X}-100$ in $\mathrm{PBS}$ ) at RT for $15 \mathrm{~min}$. After blocking at RT for $2 \mathrm{~h}$ in blocking solution (2\% BSA, 0.08\% Triton X-100 in PBS), antibody (rabbit anti-PKCद, Cell Signaling \#9368, 1:500) was incubated at $4{ }^{\circ} \mathrm{C} \mathrm{o} / \mathrm{n}$. After washing twice with PBT at RT for 15 min, cells were incubated with secondary antibody (ALEXA 647 anti-rabbit IgG, Invitrogen \#A31573, 1:500) at RT for $2 \mathrm{~h}$ and then washed with PBT and PBS. Images were taken by confocal microscope (LSM700).

\section{Electrophysiology}

For whole-cell patch-clamp recordings, rat cultured hippocampal neurons at DIV 13-14 were used for patch clamp recording. Neurons were voltage clamped at $-70 \mathrm{mV}$ for $\mathrm{mEPSC}$ recording, using a Multiclamp 700B amplifier and pClamp 10.4 software (Molecular Devices). Data were collected for $5 \mathrm{~min}$ and digitized at $10 \mathrm{kHz}$, with a $2-\mathrm{kHz}$ lowpass filter, and dizitized by Digidata 1440 16-bit A/D converter (Axon instruments). Recording pipettes $(3 \sim 4.5 \mathrm{M} \Omega$ ) were pulled with P-1000 (Sutter instrument) using a four-step protocol. First the pipettes were filled with internal solution containing the following: $145 \mathrm{mM}$ K-Gluconate, $5 \mathrm{mM} \mathrm{NaCl}, 0.2 \mathrm{mM}$ EGTA, $10 \mathrm{mM}$ HEPES, $2 \mathrm{mM}$ MgATP, $0.1 \mathrm{mM} \mathrm{Na}_{3} \mathrm{GTP}$, and $1 \mathrm{mM} \mathrm{MgCl} 2$ (pH 7.2 with $\mathrm{KOH}, 280 \sim 290 \mathrm{mOsm}$ ). For mEPSC recording, picrotoxin $(100 \mu \mathrm{M})$ and tetrodotoxin $(1 \mu \mathrm{M})$ were added to the external solution containing the following: $140 \mathrm{mM} \mathrm{NaCl}, 3 \mathrm{mM} \mathrm{KCl}, 10 \mathrm{mM}$ Glucose, $10 \mathrm{mM}$ HEPES, $2 \mathrm{mM} \mathrm{CaCl} 2,2 \mathrm{mM} \mathrm{MgCl}$. We excluded the data if its series resistant significant changes (>20\%) or it reached $15 \mathrm{M} \Omega$. Cells that need more than $200 \mathrm{pA}$ of hold current to maintain $-70 \mathrm{mV}$ were also excluded from the dataset. Data were analyzed using Clampfit 10.5 (Molecular Devices) with template match function with threshold of 3 by creating template using 50 sample traces in the data. The template was used for analyzing all the data.

\section{Results and discussion}

To explore whether PKM $\zeta$ regulates the lateral movement of AMPARs, we expressed active and inactive $\mathrm{PKM} \zeta$ mutants in cultured rat hippocampal neurons and performed single molecule live imaging of endogenous
AMPARs (Fig. 1). PKM $\zeta$ becomes fully functional through the phosphorylation of T227, which corresponds to T410 in PKCל, by PDK1 [29]. Therefore, we used the phosphomimetic form (T227E) to assess the effect of elevating PKM $\zeta$ activity. K98, which corresponds to $\mathrm{K} 281$ in $\mathrm{PKC}$, is located in the ATP-binding site of $\mathrm{PKM} \zeta$ and is essential for PKM $\zeta$ kinase activity. The expression of the $\mathrm{K} 98 \mathrm{~W}$ mutant form of $\mathrm{PKM} \zeta$ has been shown to impair memory maintenance $[15,30]$ and LTP [5]. We expressed the K98W mutant form of PKM examine the effect of hindered PKM $\zeta$ activity. Homer1C, a postsynaptic marker, fused with the fluorescent protein mCerulean3.0, was co-expressed for visualizing the transfected neurons and identifying the synaptic regions (Fig. 1b, c). We employed a TetON expression system, which was activated by doxycycline-inducible rtTA; the expression of the system was driven by a neuron-specific CaMKIIa promoter (Fig. 1b). We introduced the plasmids into cells by nucleofection before plating cells and added doxycycline into the culture media at 14-15 DIV. After 2 days of expression, we labelled endogenous surface AMPARs by brief incubation of neurons with a primary antibody against GluA2, which was followed by the incubation with a secondary antibody linked to Qdots [28]. We focused on GluA2 subunit-containing AMPARs because its synaptic incorporation is thought to be important for LTP and long-term memory maintenance [31-33].

We used a home-made program (see Methods) to measure the diffusion rates of AMPARs in an unbiased and automatic way. The relative distribution of diffusion coefficients of Qdot-labelled GluA2-containing AMPARs appeared similar to those that were obtained from a large number of AMPARs using super-resolution imaging [34]. T227E expressing neurons showed higher fraction of immobile GluA2-containing receptors, compared with control or K98W neurons, suggesting that the increase of $\mathrm{PKM} \zeta$ activity restrains the lateral movement of GluA2-containing AMPARs (Fig. 2a-d).

Next, to elucidate subcellular locations where the changes in AMPAR movement occurred, we classified the trajectories into synaptic or extrasynaptic trajectories based on the Homer1C-fused mCerulean3.0 fluorescence intensity (see Methods). In our analysis, T227E neurons showed an increase in GluA2 immobile fraction in both extrasynaptic and synaptic regions (Fig. 2e-l), suggesting that PKM $\zeta$ affected the machinery involved in the lateral movement of GluA2-containing AMPARs, regardless of their synaptic or extrasynaptic localization.

Next, we recorded the miniature excitatory synaptic transmission current (mEPSC) in these neurons to investigate whether the suppression of the lateral movement of AMPARs due to PKM $\zeta$ activity was associated with a change in synaptic transmission. Earlier work by Ron et al. (2013) [35] overexpressing PKM 

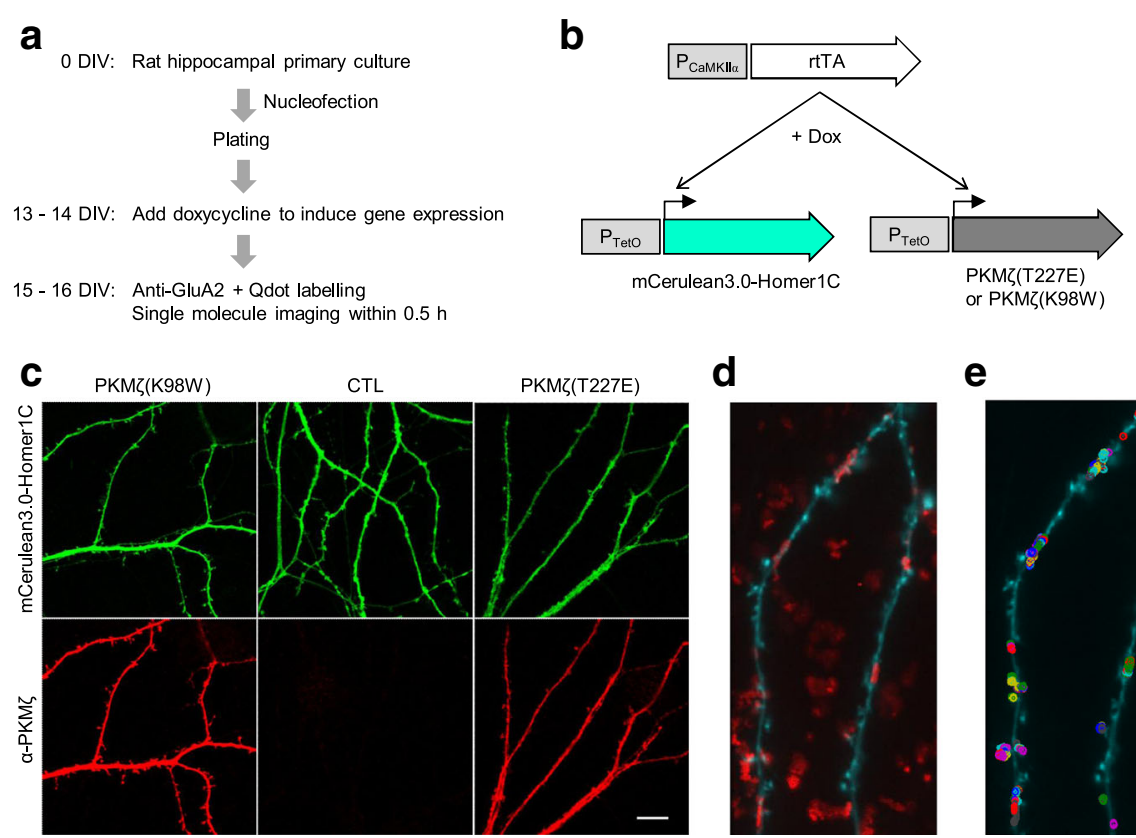

e

Fig. 1 Overexpression of active or inactive PKM in cultured rat hippocampal neurons and single molecule imaging of GluA2-containing AMPARs. a Experimental workflow. b Transgene expression using TetON system. c Representative image of fluorescence microscopy of Homer1C-fused mCerulean3.0 and anti-protein kinase C, zeta (PKCZ) immunofluorescence signals in neurons expressing active PKM (T227E), inactive PKM (K98W), or neither (CTL). d Representative image of Qdot-labelled GluA2-containing AMPARs (red, maximum intensity projection of 500 frames) and mCerulean3.0 (cyan, average image of 100 frames). (e) Qdot trajectories (open circles) observed in the dendritic region (cyan)

neocortical neurons had found a selective increase in the amplitude of the largest mEPSCs, without a change in the average mEPSC amplitude or frequency. We observed in hippocampal neurons a tendency for an increase in frequency and amplitude of the mEPSCs in PKM $\zeta$ T227E-transfected neurons although statistically nonsignificant (Fig. 3a, b), and, in line with Ron et al. (2013) [35], that the amplitudes of largest mEPSCs from each cell are higher in the PKM $\zeta$ T227E group as compared with the control and K98W neurons (Fig. 3c).

The current study provides evidence that PKM $\zeta$ restrains the lateral mobility of surface AMPARs. PKM $\zeta$ has been reported to be upregulated after learning or LTP induction, which persists for a long time [12, 36, 37]. According to our results, the upregulation of $\mathrm{PKM \zeta}$ may reduce the lateral mobility of AMPARs, thereby affecting synaptic properties. Diffusional synaptic trapping of AMPARs is thought to be crucial for LTP [38]. A previous study demonstrated that LTP stimulus induces immobilization of AMPARs via CaMKII $\alpha$. The phosphorylation of stargazin by CaMKII $\alpha$ induced the association of AMPARs with synaptic scaffolding, thereby increasing the probability of retaining synaptic AMPARs [17, 18, 22, 28]. The immobilization of AMPARs by PKM $\zeta$ upregulation, found in our study, may also contribute to the synaptic stabilization of AMPARs for LTP manifestation. In our results, expression of constitutively active PKM immobilized AMPARs in both synaptic and extrasynaptic compartments, similar to CaMKII $\alpha$ in the previous study. Although ectopic over-expression was used in both studies, physiological up-regulation of CaMKII $\alpha$ or PKM $\zeta$ levels and their actions may occur in local subcellular environments and affect the lateral mobility of the nearby AMPARs. Particularly, movement of synaptic AMPARs at potentiated spines or extrasynaptic AMPARs at spine necks nearby the potentiated spines may be restrained to increase the probability of AMPAR at the potentiated spines. These hypotheses warrant further research.

Synaptic transmission measured by the mEPSC amplitude showed an enhancement of the size of the largest mEPSCs by PKM $\zeta$ T227E and a slight tendency towards an increase in mean mEPSC, in line with prior overexpression studies $[14,35]$. These results with PKM $\zeta$ overexpression are in contrast to previous work with rapid postsynaptic perfusion of $\mathrm{PKM} \zeta$, which produces a doubling of EPSC and mEPSC size within minutes of cell breakthrough $[5,11,39]$. The small effect in our results may be partly due to a portion of neurons that do not overexpress PKM (co-transfection efficiency 80\%), or to homeostatic changes decreasing responses at synapses without PKM C. Another explanation would be that although the single synaptic responses did not change strongly, a population response to the same presynaptic stimulus could have increased further through processes 

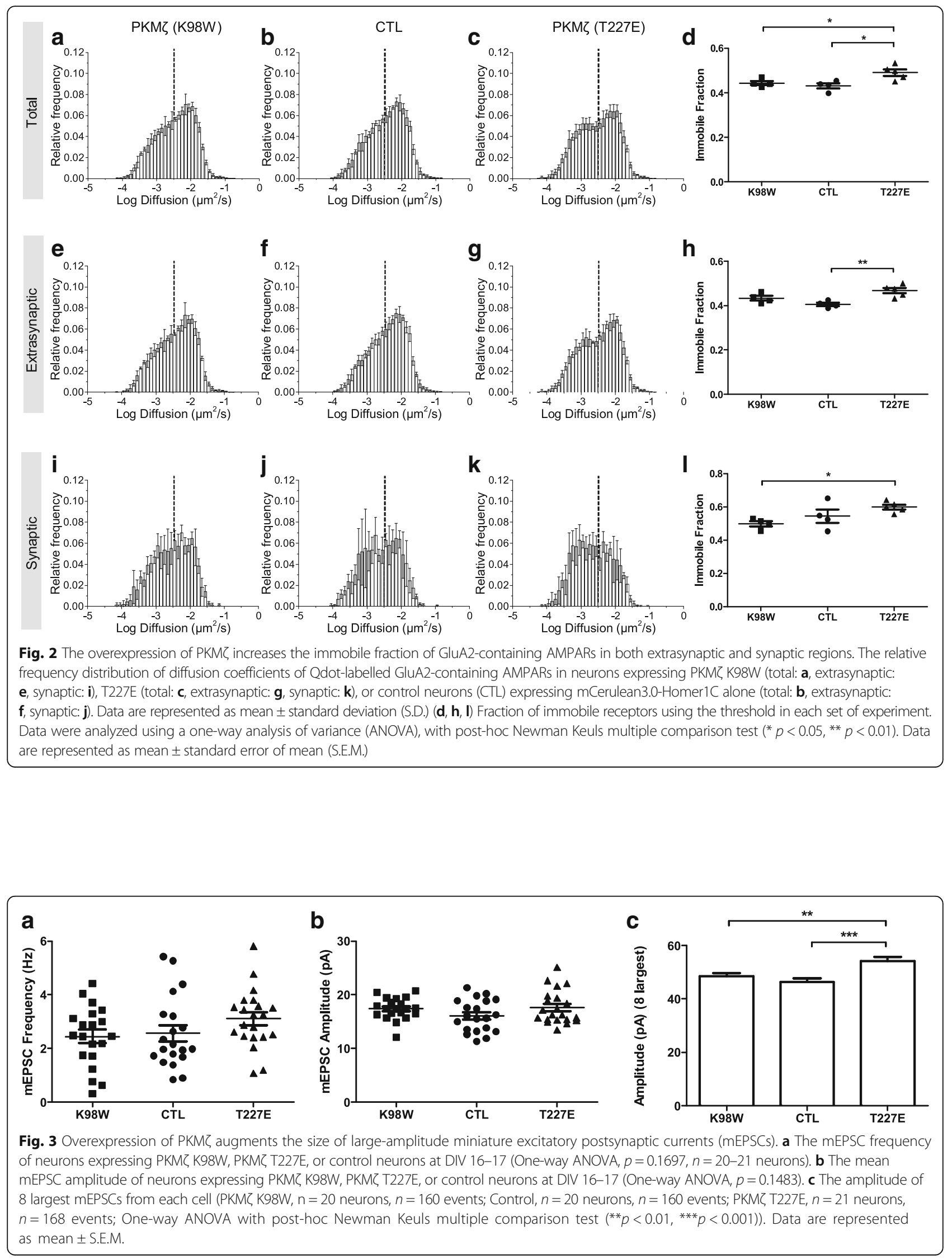
such as activating silent synapses, given that we observed the increasing tendency in both frequency and amplitude of mEPSC. In addition to the effect on the basal synaptic transmission, a previous study has shown that PKM $\zeta$ overexpression enhanced LTP [14]. Thus, as a newly synthesized plasticity-related protein (PRP), the increased PKM $\zeta$ may prime neurons to respond to other events, such as formation of synaptic tags following an LTP stimulus [40]. This highlights the possibility that the upregulation of PKM following one type of learning may prime neurons for an experience or stimulus that follows. Intriguingly, this process may involve the regulation of lateral mobility of AMPARs seen in our results.

In our results, expression of PKM $\zeta$ K98W, a dominant negative form, affected neither the lateral mobility of AMPAR nor mEPSC. Although it has no effect during the basal state, K98W may impair the changes associated with LTP when PKM $\zeta$ is upregulated and in action. Thus, our result is in line with the findings that only potentiated synaptic transmission is affected by $\mathrm{K} 98 \mathrm{~W}$ and reversed by $\mathrm{PKM \zeta} \mathrm{inhibitors,} \mathrm{whereas} \mathrm{basal} \mathrm{synaptic}$ transmission is not $[5,6]$.

In summary, we used the single Qdot live-imaging analysis to investigate the effect of PKM $\zeta$ overexpression on the lateral movement of GluA2-containing AMPARs. $\mathrm{PKM} \zeta$ overexpression decreased the lateral diffusion of GluA2-containing AMPARs at the synapse. This finding highlights a novel molecular mechanism that may underlie learning and memory. The PKM $\zeta$ substrates and detailed mechanisms mediating the effect of AMPAR immobilization will be interesting to investigate in the future.

\begin{abstract}
Abbreviations
AMPA: a-amino-3-hydroxy-5-methyl-4-isoxazolepropionic acid; LTP: Long term potentiation; mEPSC: Miniature excitatory post-synaptic current; PKMZ: Protein Kinase M zeta; Qdot: Quantum-dot; ZIP: Zeta inhibitory peptide

\section{Acknowledgments}

Not applicable.

\section{Funding}

This work was supported by a Creative Research Initiative grant (Physical Genetics Laboratory, 2009-0081562), which was awarded to S.H., and by a National Honor Scientist Program award to B.-K.K. (NRF2012R1A3A1050385) from the National Research Foundation of Korea, and 2R37MH057068 and R01 DA034970 to T.C.S.
\end{abstract}

\section{Availability of data and materials}

The data supporting the findings of this study are included within the article.

\section{Authors' contributions}

$\mathrm{N}-\mathrm{KY}, \mathrm{JS}, \mathrm{HU}, \mathrm{SH}, \mathrm{B}-\mathrm{KK}$ designed the research; N-KY, JS, HU, J-HC, and SB performed the research; N-KY, JS, HU analyzed data; and N-KY, JS, TCS, HU, $\mathrm{SH}, \mathrm{B}-\mathrm{KK}$ wrote the paper. All authors read and approved the final manuscript.

\section{Ethics approval and consent to participate}

All surgical and experimental procedures were reviewed and approved by the Institutional Animal Care and Use Committee (IACUC) at Seoul National University. Consent to participate is not applicable.
Consent for publication

Not applicable.

\section{Competing interests}

The authors declare that they have no competing interests.

\section{Publisher's Note}

Springer Nature remains neutral with regard to jurisdictional claims in published maps and institutional affiliations.

\section{Author details}

${ }^{1}$ Department of Biological Sciences, College of Natural Sciences, Seoul National University, Seoul, South Korea. ${ }^{2}$ Department of Physics and Astronomy, Seoul National University, Seoul, South Korea. ${ }^{3}$ National Center for Creative Research Initiatives, Seoul National University, Seoul, South Korea. ${ }^{4}$ Institute of Applied Physics, Seoul National University, Seoul, South Korea. ${ }^{5}$ Department of Biophysics and Chemical Biology, Seoul National University, Seoul, South Korea. ${ }^{6}$ Institute of Nano Science and Technology, Hanyang University, Seoul, South Korea. ${ }^{7}$ Department of Physiology \& Pharmacology, SUNY Downstate Medical Center, 450 Clarkson Ave, Brooklyn, NY 11203, USA ${ }^{8}$ Department of Anesthesiology, SUNY Downstate Medical Center, 450 Clarkson Ave, Brooklyn, NY 11203, USA. ${ }^{9}$ Department of Neurology, SUNY Downstate Medical Center, 450 Clarkson Ave, Brooklyn, NY 11203, USA.

${ }^{10}$ Center for Neuron and Disease, Frontier Institute of Life Science and of Science and Technology, Xi'an Jiaotong University, Xi'an, China.

Received: 22 September 2017 Accepted: 8 November 2017

Published online: 29 November 2017

\section{References}

1. Park P, Volianskis A, Sanderson TM, Bortolotto ZA, Jane DE, Zhuo M, et al. NMDA receptor-dependent long-term potentiation comprises a family of temporally overlapping forms of synaptic plasticity that are induced by different patterns of stimulation. Philos Trans R Soc Lond Ser B Biol Sci. 2014;369:20130131.

2. Lee S-H, Shim J, Cheong Y-H, Choi S-L, Jun Y-W, Lee S-H, et al. ApCPEB4, a non-prion domain containing homolog of $A p C P E B$, is involved in the initiation of long-term facilitation. Mol Brain. 2016;9:91.

3. Kandel ER. The molecular biology of memory: CAMP, PKA, CRE, CREB-1, CREB-2, and CPEB. Mol Brain. 2012;5:14.

4. Sacktor TC. Memory maintenance by PKM — - an evolutionary perspective. Mol Brain. 2012;5:30.

5. Ling DSF, Benardo LS, Serrano PA, Blace N, Kelly MT, Crary JF, et al. Protein kinase $M \zeta$ is necessary and sufficient for LTP maintenance. Nat Neurosci. 2002;5:295-6.

6. Pastalkova E, Serrano P, Pinkhasova D, Wallace E, Fenton AA, Sacktor TC. Storage of spatial information by the maintenance mechanism of LTP. Science. 2006:313:1141-4.

7. Sacktor TC. How does PKM $\zeta$ maintain long-term memory? Nat Rev Neurosci. 2011;12:9-15.

8. Li X-Y, Ko H-G, Chen T, Descalzi G, Koga K, Wang H, et al. Alleviating neuropathic pain hypersensitivity by inhibiting PKMZ in the anterior cingulate cortex. Science. 2010;330:1400-4.

9. Volk LJ, Bachman JL, Johnson R, Yu Y, Huganir RL. PKM- $\zeta$ is not required for hippocampal synaptic plasticity, learning and memory. Nature. 2013:493:420-3.

10. Lee AM, Kanter BR, Wang D, Lim JP, Zou ME, Qiu C, et al. Prkcz null mice show normal learning and memory. Nature. 2013;493:416-9.

11. Tsokas $P$, Hsieh C, Yao Y, Lesburguères E, Wallace EJC, Tcherepanov A, et al. Compensation for PKM $\zeta$ in long-term potentiation and spatial long-term memory in mutant mice. elife. 2016;5:12677.

12. Hsieh C, Tsokas P, Serrano P, Hernández Al, Tian D, Cottrell JE, et al. Persistent increased PKM in long-term and remote spatial memory. Neurobiol Learn Mem. 2017;138:135-44.

13. Wang $S$, Sheng T, Ren $S$, Tian T, Lu W. Distinct roles of PKCI $/ \lambda$ and PKM $Z$ in the initiation and maintenance of hippocampal long-term potentiation and memory. Cell Rep. 2016;16:1954-61.

14. Schuette SRM, Fernández-Fernández D, Lamla T, Rosenbrock H, Hobson S. Overexpression of protein kinase $M \zeta$ in the hippocampus enhances long-term potentiation and long-term contextual but not cued fear memory in rats. J Neurosci. 2016;36:4313-24. 
15. Shema R, Haramati S, Ron S, Hazvi S, Chen A, Sacktor TC, Dudai Y. Enhancement of consolidated long-term memory by overexpression of protein kinase $M \zeta$ in the neocortex. Science. 2011;331:1207-10.

16. Xue $Y-X$, Zhu Z-Z, Han H-B, Liu J-F, Meng S-Q, Chen C, et al. Overexpression of protein kinase $M \zeta$ in the prelimbic cortex enhances the formation of long-term fear memory. Neuropsychopharmacology. 2015:40:2146-56.

17. Malinow R, Malenka RC. AMPA receptor trafficking and synaptic plasticity. Annu Rev Neuroscience. 2002;25:103-26.

18. Malinow R. AMPA receptor trafficking and long-term potentiation. Philos Trans R Soc Lond Ser B Biol Sci. 2003;358:707-14.

19. Collingridge GL, Olsen RW, Peters J, Spedding M. A nomenclature for ligand-gated ion channels. Neuropharmacology. 2009;56:2-5.

20. Zhang T-T, Shen F-Y, Ma L-Q, Wen W, Wang B, Peng Y-Z, et al. Potentiation of synaptic transmission in rat anterior cingulate cortex by chronic itch. Mol Brain. 2016;9:73.

21. Cui L, Sun W, Yu M, Li N, Guo L, Gu H, et al. Disrupted-in-schizophrenia1 (DISC1) L100P mutation alters synaptic transmission and plasticity in the hippocampus and causes recognition memory deficits. Mol Brain. 2016;9:89.

22. Bredt DS, Nicoll RA. AMPA receptor trafficking at excitatory synapses. Neuron. 2003;40:361-79.

23. Choquet D, Triller A. The dynamic synapse. Neuron. 2013;80:691-703.

24. Collingridge GL, Isaac JTR, Wang YT. Receptor trafficking and synaptic plasticity. Nat Rev Neurosci. 2004;5:952-62.

25. Yao Y, Kelly MT, Sajikumar S, Serrano P, Tian D, Bergold PJ, et al. PKM maintains late long-term potentiation by $\mathrm{N}$-ethylmaleimide-sensitive factor/ GluR2-dependent trafficking of postsynaptic AMPA receptors. J Neurosci. 2008;28:7820-7.

26. Yu N-K, Kim HF, Shim J, Kim S, Kim DW, Kwak C, et al. A transducible nuclear/nucleolar protein, $\mathrm{mLLP}$, regulates neuronal morphogenesis and synaptic transmission. Sci Rep. 2016;6:22892.

27. Yildiz A, Forkey JN, McKinney SA, Ha T, Goldman YE, Selvin PR. Myosin V walks hand-over-hand: single fluorophore imaging with 1.5-nm localization. Science. 2003;300:2061-5.

28. Opazo P, Labrecque S, Tigaret CM, Frouin A, Wiseman PW, De Koninck P, et al. CaMKII triggers the diffusional trapping of surface AMPARs through phosphorylation of stargazin. Neuron. 2010;67:239-52.

29. Kelly MT, Crary JF, Sacktor TC. Regulation of protein kinase M $M$ synthesis by multiple kinases in long-term potentiation. J Neurosci. 2007:27:3439-44.

30. Drier EA, Tello MK, Cowan M, Wu P, Blace N, Sacktor TC, et al. Memory enhancement and formation by atypical PKM activity in Drosophila Melanogaster. Nat Neurosci. 2002;5:316-24.

31. Hardt O, Nader K, Wang YT. GluA2-dependent AMPA receptor endocytosis and the decay of early and late long-term potentiation: possible mechanisms for forgetting of short- and long-term memories. Philos Trans R Soc Lond Ser B Biol Sci 2014;369:20130141-1.

32. Migues PV, Liu L, Archbold GEB, Einarsson EÖ, Wong J, Bonasia K, et al. Blocking synaptic removal of GluA2-containing AMPA receptors prevents the natural forgetting of long-term memories. J Neurosci. 2016;36:3481-94.

33. Migues PV, Hardt O, Finnie P, Wang YW, Nader K. The maintenance of long-term memory in the hippocampus depends on the interaction between N-ethylmaleimide-sensitive factor and GluA2. Hippocampus. 2014;24:1112-9.

34. Nair D, Hosy E, Petersen JD, Constals A, Giannone G, Choquet D, et al. Super-resolution imaging reveals that AMPA receptors inside synapses are dynamically organized in nanodomains regulated by PSD95. J Neurosci. 2013;33:13204-24

35. Ron S, Dudai Y, Segal M. Overexpression of PKM function of dendritic spines in cultured cortical neurons. Cereb Cortex 2012:22:2519-28

36. Palida SF, Butko MT, Ngo JT, Mackey MR, Gross LA, Ellisman MH, et al. PKM , but not PKC $\lambda$, is rapidly synthesized and degraded at the neuronal synapse. J Neurosci. 2015;35:7736-49.

37. Kelly MT, Yao Y, Sondhi R, Sacktor TC. Actin polymerization regulates the synthesis of PKM in LTP. Neuropharmacology. 2007:52:41-5.

38. Ehlers MD, Heine $M, G$ roc $L$, Lee $M-C$, Choquet D. Diffusional trapping of GluR1 AMPA receptors by input-specific synaptic activity. Neuron. 2007:54:447-60.
39. Ling DS, Benardo LS, Sacktor TC. Protein kinase $M \zeta$ enhances excitatory synaptic transmission by increasing the number of active postsynaptic AMPA receptors. Hippocampus. 2006;16:443-52.

40. Sajikumar S, Navakkode S, Sacktor TC, Frey JU. Synaptic tagging and cross-tagging: the role of protein kinase $M \zeta$ in maintaining long-term potentiation but not long-term depression. J Neurosci. 2005;25:5750-6.

\section{Submit your next manuscript to BioMed Central and we will help you at every step:}

- We accept pre-submission inquiries

- Our selector tool helps you to find the most relevant journal

- We provide round the clock customer support

- Convenient online submission

- Thorough peer review

- Inclusion in PubMed and all major indexing services

- Maximum visibility for your research

Submit your manuscript at www.biomedcentral.com/submit
Biomed Central 